\title{
U.S. DEPARTMENT OF ENERGY \\ 2018 RACE TO ZERO \\ Student Design Competition Guide
}

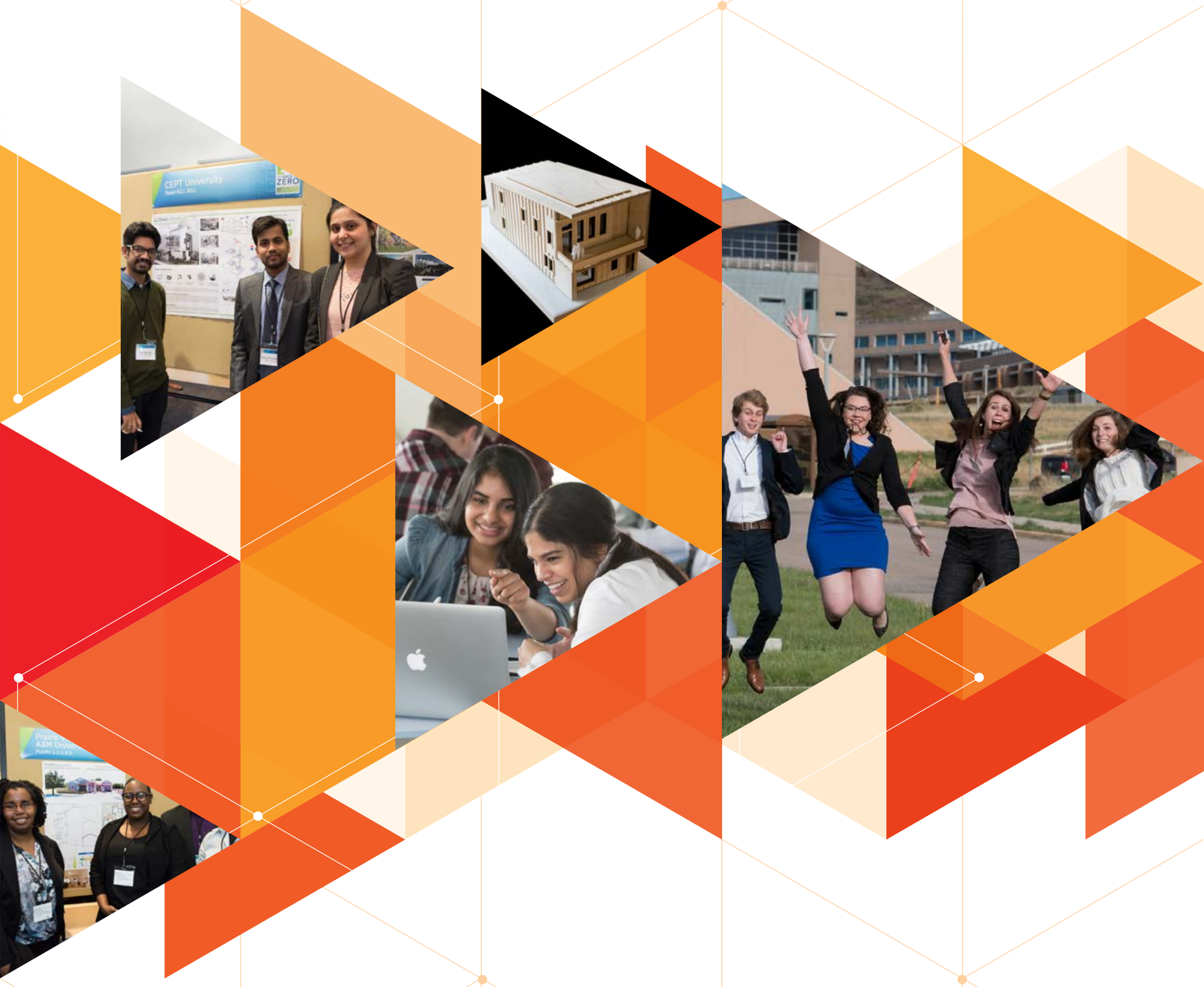




\section{Foreword}

This is an exciting time-a time when zero energy ready buildings have become achievable and economical. Dare I say, a zero energy ready movement has begun?

In response to this movement, the U.S. Department of Energy (DOE) Race to Zero Student Design Competition (Race to Zero) seeks to inspire collegiate students to become the next generation of building professionals who are prepared to meet this growing imperative for environmentally responsive buildings. Specifically, this competition helps provide future architects, engineers, construction managers, and entrepreneurs with the skills and experience needed to fully integrate building science into ultra-efficient buildings that are cost-effective and meet the design constraints of the mainstream building industry. Yes, that winning formula of performance plus cost plus design.

It's hard to believe we are about to enter our fifth Race to Zero. And each year I continue to be inspired and energized by the participating student teams that consistently exceed all of our expectations. A new face joining the organizers is my colleague, Sarah Zaleski. We welcome her expertise as we add a new commercial design contest this year. I know Sarah will be as impressed as I have been with the outstanding technical skills, creativity, collaboration, enthusiasm, commitment, and passion demonstrated by the teams. And let me note that the impressive quality of participating students is also noticed by our outstanding sponsors and jurors. I know this from watching the significant growth in interest engaging students about future job opportunities during the Career Connections session at the end of each competition.

We are so excited you are taking that all-important first step to become part of the zero energy ready buildings movement. This competition guide is developed and updated every year to help ensure your success. We hope you take advantage of it, and I look forward to seeing your team's design at the 2018 event!
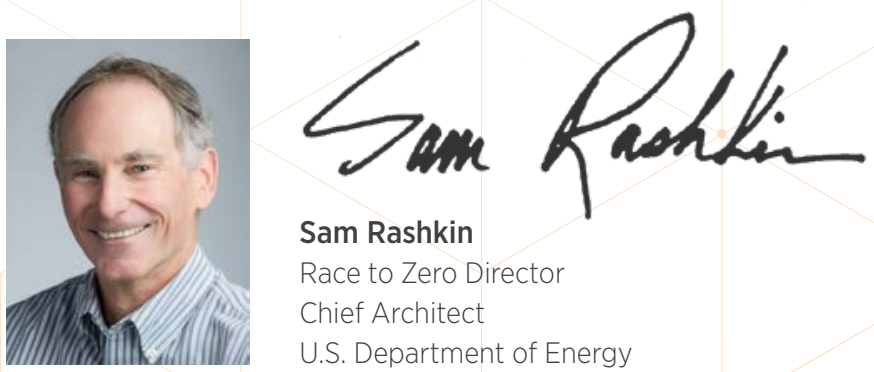

\section{Sam Rashkin}

Race to Zero Director

Chief Architect

U.S. Department of Energy

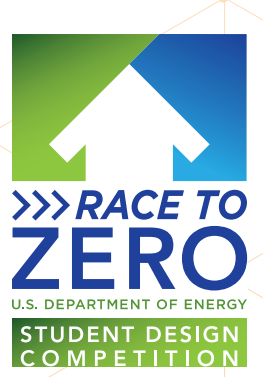




\section{TABLE OF CONTENTS}

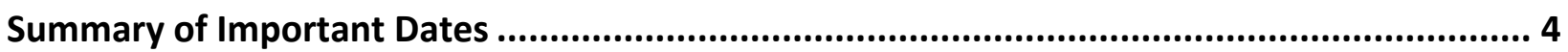

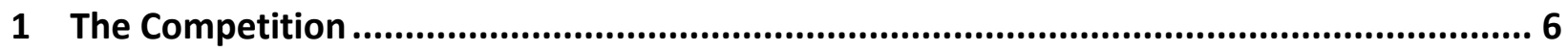

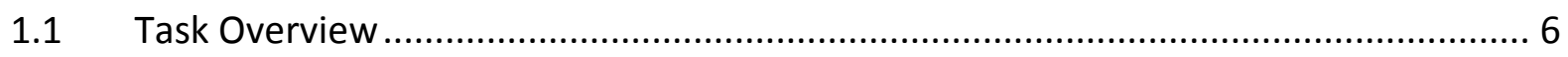

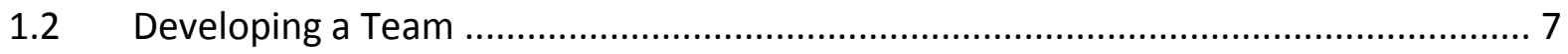

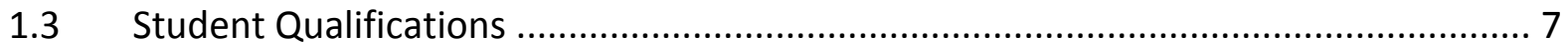

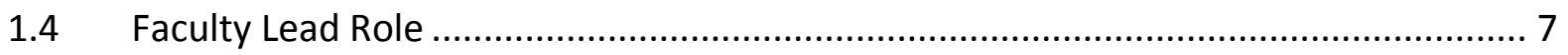

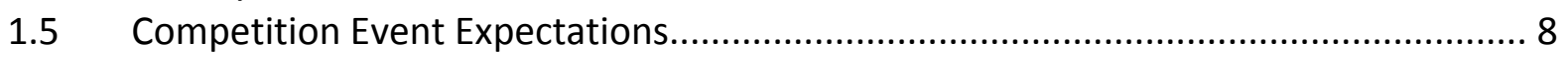

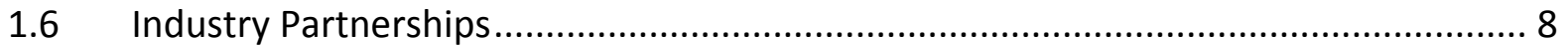

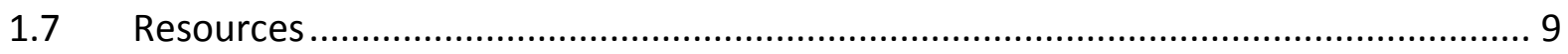

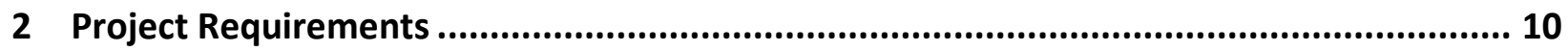

$2.1 \quad$ Design Contests................................................................................................. 10

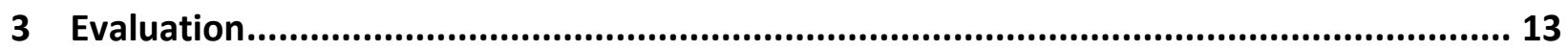

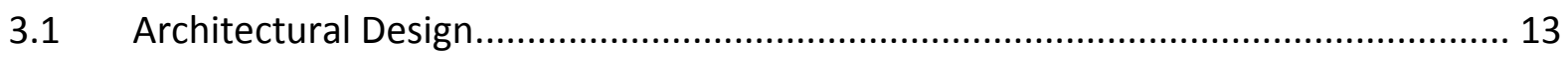

3.2 Interior Design, Lighting, Plug Loads, and Appliances .............................................. 14

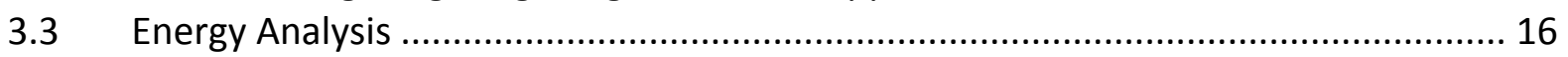

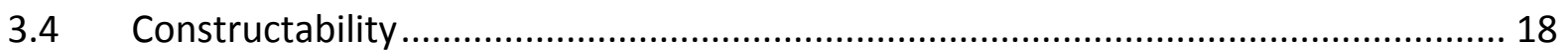

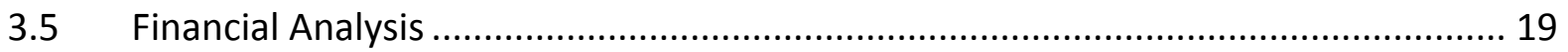

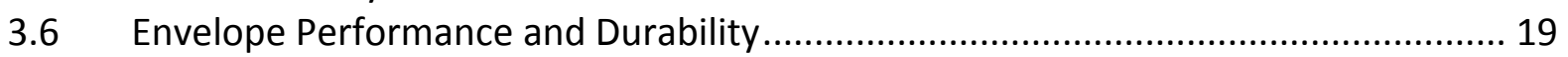

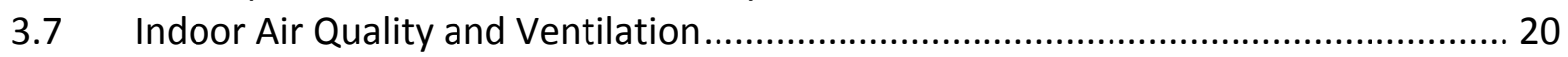

3.8 Mechanical, Electrical, and Plumbing Design ........................................................ 21

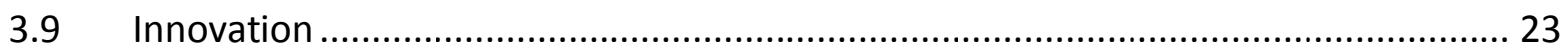

3.10 Presentation and Documentation Quality .......................................................... 24

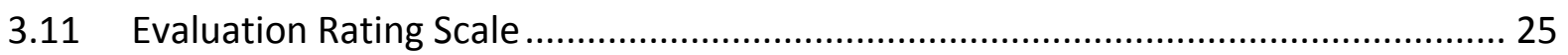

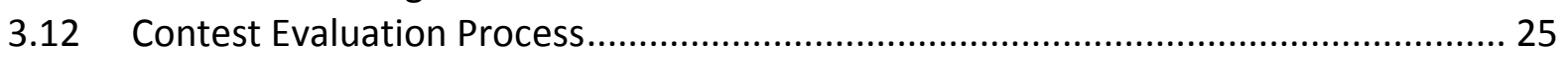

3.13 Grand Jury Evaluation Process............................................................................ 25

Appendix A: Project Introduction Submission Instructions ....................................................... 27

Appendix B: Project Progress Report Submission Instructions ................................................. 29

Appendix C: Project Report Submission Instructions .............................................................. 31

Appendix D: Project Presentations Submission Instructions .................................................... 34

Appendix E: Project Poster Submission Instructions ............................................................... 35

Appendix F: Electronic File-Naming Instructions .................................................................. 36

Competition Guide Authors: NREL's Rachel Romero, Sara Farrar, Joe Simon, and Paul Torcellini 


\section{Summary of Important Dates}

Note the following milestones for the 2018 Race to Zero competition:

- July 11, 2017: The 2018 Race to Zero Competition Guide is released, and the team application is open via the Race to Zero website.

- When each team completes their application, the team is provided access to competition communications and resources, including building science training and energy modeling software.

- November 7, 2017, 5:00 p.m. (Eastern Standard Time; EST): The deadline by which all teams must complete their team application online, including indicating which contest the team wants to enter and submit an optional three-page Project Introduction. All teams are accepted as participants, whether or not a Project Introduction is submitted.

- Teams that submit a Project Introduction are provided feedback on project compliance and Race to Zero requirements. The requirements for the Project Introduction are detailed in Appendix A.

- Each team pays a nonrefundable $\$ 100$ fee, identifies a faculty lead or student team lead, and submits a preliminary roster of student team members.

- If there are more than 8 teams applying for any contest, the organizers notify all teams of the distribution and allow up to 7 days for teams to select a different contest from the options available on the Race to Zero Groups.io portal, if they would like to do so.

- If a team member who is not a U.S. citizen wants to participate in person at the competition event held on the National Renewable Energy Laboratory (NREL) campus, each affected person must submit a Foreign National Data Card. Additional information and requirements are provided in the online team application site.

- January 31, 2018: The final 2018 Race to Zero Competition Guide is released.

- February 20, 2018, 5:00 p.m. EST: The deadline by which all teams must complete the Project Progress Report and indicate which team members have completed the building science training online or have received a waiver from their faculty lead.

- The Project Progress Report, as detailed in Appendix B, must be submitted via the file submission link posted to the Race to Zero Groups.io portal.

- If more than 8 teams submit to one contest category, then within 10 days entries are evaluated against criteria indicated in Appendix B. Based on the Project Progress Report evaluation, up to eight teams per contest category are invited to participate in the final competition.

- Event registration opens. At least one member-but not more than five members total-from each team may attend in person, including students and faculty lead and/or advisor. 
- April 3, 2018, 5:00 p.m. (Eastern Daylight Time; EDT): The deadline by which teams must submit their Project Report.

- The Project Report, as detailed in Appendix C, must be submitted via the file submission link posted to the Race to Zero Groups.io portal.

○ Event registration closes. On-site or late event registration will not be offered.

- April 17, 2018, 5:00 p.m. (EDT): The deadline by which teams must submit their Project Presentations (both contest and grand jury presentations) and optional posters, as detailed in Appendix D and Appendix E, respectively. Presentations will not be accepted after this date.

- April 20-22, 2018: Finalist teams compete as they present to industry leaders on the NREL main campus in Golden, Colorado. 


\section{The Competition}

Participants in the U.S. Department of Energy (DOE) Race to Zero Student Design Competition (Race to Zero) prepare creative solutions for real-world issues in the building industry. Accepted teams complete a design project and attend the competition event, where they present their designs to a panel of industry expert jurors, compare their efforts to those of other teams, learn from presentations by thought leaders, and engage with a variety of organizations about energy careers. The winning teams are recognized at an Awards Banquet, and the winning designs are published on the Race to Zero website. The competition and winners are promoted through a variety of media outreach efforts, which provide participants and their collegiate institutions an opportunity for national exposure. Collegiate institutions that participate in the Race to Zero are recognized as leaders that are producing career-ready young professionals with cuttingedge skills. Builders who collaborate with teams gain national and local recognition and have the opportunity to interact with knowledgeable future design and construction professionals.

The Race to Zero is designed to encourage student participation for one or two academic semesters, concluding in the spring with the Project Presentation and Awards Banquet.

View Previous Years' Winners

2017 Race to Zero Results

2016 Race to Zero Results

2015 Race to Zero Results

\subsection{Task Overview}

- Read this Race to Zero Competition Guide, and form a team.

- Review the 2017 winning teams' presentations to inform efforts.

- Submit a team application via the link provided on the Race to Zero website.

- Ensure that all team members have access to the Race to Zero Groups.io portal, where competition updates are posted regularly.

- Ensure that all student team members complete the DOE building science training course online or receive a waiver from the team's faculty lead if equivalent training is provided as part of the student's curriculum.

- The building science training coursework from world-renowned experts is provided at no cost to every team member.

- Access instructions are available on the Race to Zero Groups.io portal.

- The curriculum includes topics such as enclosure fundamentals; rain control; air flow control; heat flow control; vapor and condensation control; roofs; ventilation and air pressure management; windows; durable, healthy, efficient 
housing; unique solutions (optional); multifamily/multiunit housing (optional); and elementary schools (optional).

- Identify subject areas in which industry partnership is needed or wanted.

- Study the Race to Zero resources listed in this guide.

- Consult the Race to Zero website and Groups.io portal for updates and announcements.

- Attend optional Race to Zero competition webinars as advertised on the Race to Zero Groups.io portal for technical design and competition guidance. These webinars will also be available as recordings posted to the portal.

- Design and document a project compliant with the requirements listed in this guide.

- Submit all materials by the deadlines. Note that all deadlines are 5:00 p.m. Eastern Time.

- Submit your questions to racetozero@nrel.gov.

\subsection{Developing a Team}

Each team must be associated with a collegiate institution and include a faculty lead. The competition is open to all universities and degree-issuing institutions, including community colleges. International institutions are welcome to participate. Each team must have at least three current students, with one student designated as the student team lead. Teams are encouraged to be multidisciplinary. Multiple collegiate institutions may combine to form a team. A collegiate institution may submit only one team application per design contest (see Section 2, Project Requirements). The Team Application costs $\$ 100$ per team and is nonrefundable.

\subsection{Student Qualifications}

Great teams are cross-functional. Student team members can be from any discipline and any level of collegiate schooling. Past teams have included students who majored in fields such as architecture, engineering, building science, construction management, interior design, marketing, management, and landscape architecture. Each student shall be pursuing a degree and enrolled in at least one class at a participating collegiate institution at the time of the Project Presentation.

\subsection{Faculty Lead Role}

The faculty lead, along with the student team lead, is responsible for communicating competition details from the Race to Zero organizers to the team members. A team may have more than one faculty advisor, but one faculty lead must be designated to serve as a primary contact, oversee the team, and maintain responsibility for students completing the building science training or equivalent curriculum. The faculty lead is encouraged to closely engage with the students on the project. The faculty lead provides support in many areas, including:

- Ensuring familiarity with the Race to Zero Competition Guide and additional guidance as appropriate. 
- Ensuring that all student team members complete the building science training.

The faculty lead must ensure the team meets this requirement or indicate that building science is part of the core curriculum. Also, by understanding the strengths of the students, the faculty lead can encourage the students to view additional webinars and access training materials that are most relevant to the team.

- Ensuring that the necessary information is provided to team members who will be on-site at the competition event. The faculty lead may attend the competition in person or join the presentation remotely.

\subsection{Competition Event Expectations}

After evaluating the Project Progress Reports, up to 40 teams are invited to attend the competition. The event provides a rich experience for on-site participants through networking opportunities and attending other team and professional presentations. The organizers expect each team to send at least one in-person student to the competition. The faculty lead is encouraged, but not required, to attend.

We encourage all students who are on-site to participate in the team presentation; faculty may not participate in the team presentation.

The organizers do not provide financial assistance for lodging or travel expenses. A block of rooms at a hotel near the NREL campus will be available at a discounted rate. Note that meals and snacks are provided at no cost over the weekend. This includes the Awards Banquet, which is expected to be held at the same hotel.

Indicate when registering for the competition if a team is interested in bringing an architectural-scale model. The models may be on display during the team's contest presentation and the Poster Session. These models are optional; all shipping/transportation costs are the responsibility of the teams.

\subsection{Industry Partnerships}

Industry partnerships are encouraged to provide a market-ready perspective for proposed design solutions and to help select and integrate building systems. In this competition, the term market-ready is understood to be a building design that can be constructed in today's market by typical trade contractors and at reasonable cost of ownership in the neighborhood proposed for its location.

Teams are encouraged to engage with industry professionals such as builders, architects, city officials, contractors, developers, energy auditors, engineers, or tradespeople in areas such as site development, codes, construction, building materials, mechanical systems, lighting systems, financing, and sales. These partners can help inform the students' decision-making processes and review the project. 


\subsection{Resources}

DOE Building America Solution Center

DOE Building Technologies Office, Building Science Education

Commercial Buildings Resource Database

Buildings Catalog

DOE Zero Energy Ready Home National Program Requirements (Rev. 06)

DOE Zero Energy Buildings Resource Hub

Excellence in Building Science Education

U.S. Department of Education Green Ribbon Schools

National Association of Homebuilders

The American Institute of Architects (AIA)

ASHRAE

Air Conditioning Contractors of America (ACCA)

Indoor Air Quality Association

Association of Energy Engineers

National Association of Affordable Housing Lenders

National Association of Realtors 


\section{Project Requirements}

A zero energy ready building is a high-performance building so energy-efficient that a renewable energy system could offset all of the building's annual energy consumption.

Teams must demonstrate the effective integration of building science principles and best practice guidelines for the building envelope and mechanical systems.

For the Race to Zero, teams may develop projects based on updates of designs from builders or develop original work. Teams may also retrofit or modernize an existing building. Eligible scenarios are varied, though the submission must conform to the conditions in Section 2.1.

Buildings are often subject to local, state, and national codes or standards governing topics such as minimum bedroom size, fire protection requirements, classroom size, restroom locations and quantities, or additional specific requirements. If there are conflicts between the Race to Zero contest conditions and local regulations, the local regulations supersede and teams should clearly document these local requirements in their Project Report.

Note: English units of measurement are preferred; however, a submission with metric units would be accepted. If metric units are used, state metric units first, followed by English equivalents in parentheses. Example: 38.1 meters (125 feet). For quick online conversions of English units of measurement to metric units, see the Digital Dutch Unit Converter or the Internet French Property Measuring Units Converter Table.

\subsection{Design Contests}

The Race to Zero comprises five design contests: four residential building types and one commercial building type. Each collegiate institution may submit an application for up to one team per contest.

In the Project Report, each team selects and defines a specific location, building lot or site, and neighborhood characteristics as context for the building design and its relationship to surrounding structures and the community.

The five design contests are:

\section{Residential}

\section{Suburban Single-Family (SSF)}

a. Size: 1,000-3,000 square feet (93-279 square meters)

b. Lot: 4,000 square feet (372 square meters) minimum

c. Meets or exceeds the DOE Zero Energy Ready Home National Program Requirements (Rev. 06)

\section{Urban Single-Family (USF)}


a. Size: $600-2,500$ square feet (56-232 square meters)

b. Lot: 5,000 square feet $(1,524$ square meters) maximum

c. Meets or exceeds the DOE Zero Energy Ready Home National Program Requirements (Rev. 06)

3. Attached Housing (two to six units, duplex or town-house style) (AH)

a. Size: 500-2,500 square feet (46-232 square meters) per dwelling unit

b. Lot: 3,000 square feet ( 279 square meters) maximum per dwelling unit

c. Meets or exceeds the DOE Zero Energy Ready Home National Program Requirements (Rev. 06)

\section{Small Multifamily (three or fewer stories above grade) (SMF)}

a. Size: 350-2,000 square feet (33-186 square meters) per dwelling unit

b. Lot: No minimum or maximum

c. Meets or exceeds the DOE Zero Energy Ready Home National Program Requirements (Rev. 06)

\section{Commercial}

\section{Elementary School (ES)}

a. Occupancy: 300-600 students, equally distributed in grades kindergarten through fifth; 20-30 students per classroom

b. Lot: 15 acres $(60,703$ square meters) maximum

c. In addition to the classrooms, the following spaces must be included:

i. Teacher work area (or lounge)

ii. Office/administration area

iii. Gym/recreation area

iv. Music room

v. Art room

vi. Library/media center

vii. Cafeteria, which could be combined with the gym/recreation area, if desired

viii. Kitchen/service area, which could be used for light food preparation without cooking or ventilation requirements, if desired

d. The energy use intensity (EUI) target before renewables must be less than that shown in Table 2 in the Technical Feasibility Study for Zero Energy K-12 Schools for the appropriate climate zone. 


\subsubsection{Residential Contests}

A dwelling unit, as defined by the 2012 International Energy Conservation Code, is a single unit that provides complete independent living facilities for one or more persons, including permanent provisions for living, sleeping, eating, cooking, and sanitation. Total area compliance should be verified using ANSI Z765-2013, which states that the finished area is the sum of the finished and conditioned areas measured at the floor level to the exterior finished surface of the outside walls.

Renewable energy should be considered in some form, but it is not required to be on-site. If onsite generation is not feasible, other options-such as purchasing renewable energy certificates or participating in a community renewables project-should be considered, and the associated costs should be factored into the financial analysis.

\subsubsection{Commercial Contest}

For this contest, an elementary school is defined as a complete educational facility for grades kindergarten through fifth, and it includes permanent provisions for a cafeteria; gym; offices; classrooms; and other support functions, such as mechanical spaces, circulation, and restrooms. For commercial buildings, gross area is calculated as the total conditioned space within the exterior dimension of the finished space enclosed by the outside walls.

The school and site should be designed such that sufficient renewable energy could be installed on-site with sufficient capacity so the "actual annual delivered energy is less than or equal to the on-site renewable exported energy" as defined by A Common Definition for Zero Energy Buildings. 


\section{Evaluation}

Projects submitted to Race to Zero demonstrate competency by applying principles of building science and best practice solutions. The teams are assessed on their Project Report submissions, including the design and technical documentation, project plans, reports on required analyses, and the quality and content of their presentations. These submissions should demonstrate the team's ability to design, analyze, and plan for the construction of quality, highperformance buildings.

The jurors evaluate how well teams meet or exceed each evaluation parameter criteria and complete the requirements of the project submission.

The project submissions are evaluated by jurors according to the 10 parameters in Table 1. Jurors score each parameter on a scale from 0-10 as outlined in Section 3.11, Evaluation Rating Scale.

Table 1. Evaluation Parameters

\begin{tabular}{lc}
\hline Evaluation Parameter & $\begin{array}{c}\text { Available } \\
\text { Points }\end{array}$ \\
\hline 1. Architectural Design & 10 \\
2. Interior Design, Lighting, Plug Loads, and Appliances & 10 \\
3. Energy Analysis & 10 \\
4. Constructability & 10 \\
5. Financial Analysis & 10 \\
6. Envelope Performance and Durability & 10 \\
7. Indoor Air Quality and Ventilation & 10 \\
8. Mechanical, Electrical, and Plumbing Systems Design & 10 \\
9. Innovation & 10 \\
10. Presentation and Documentation Quality & 10 \\
\hline
\end{tabular}

\subsection{Architectural Design}

The zero energy ready level of building performance will achieve meaningful market acceptance only when it is integrated with architectural designs that meet or exceed industry aesthetic and functional expectations and requirements.

\subsubsection{Criteria}

The jury evaluates each submission according to the following criteria:

- Quality of the architectural design and project appearance

- Extent to which the design responds to the building and energy performance requirements, site, natural comfort, space utilization, careful integration of building systems, and connection to the outdoors 
- How well the design approach responds to relevant national, regional, and local programs and knowledge

- The general success of the team's approach to integrating high-performance building science principles within an architecturally appealing design

- Effective design and specifications of materials, products, and building elements.

\subsubsection{Resources}

DOE Zero Energy Ready Home

DOE Guidelines for Participating in the DOE Zero Energy Ready Home

ENERGY STAR Certified New Homes

DOE Zero Energy Ready Home Recommended Quality Management Provisions

AIA Committee on the Environment Top Ten Awards

$\underline{\text { WELL Building Standard }}$

Architecture 2030

ASHRAE Advanced and Zero Energy Design Guides

New Building Institute Five Steps to Net Zero Energy

Leadership in Energy and Environmental Design (LEED) V4

\subsection{Interior Design, Lighting, Plug Loads, and Appliances}

Creative and technical solutions are applied within a structure to achieve a successful interior environment. These solutions must be functional, enhance the quality of life and culture of the occupants, and be aesthetically attractive. Considering the environmental sustainability of materials used in the interior design is encouraged.

Additionally, thoughtful selection of lighting, plug loads, and appliances can significantly affect the overall energy use. This is typically achieved by using ENERGY STAR ${ }^{\circledR}$-certified or better fixtures and appliances throughout the building.

\subsubsection{Criteria}

The jury evaluates each submission according to the following criteria:

- Interior design's functionality, attractiveness, and enhancement of the occupants' quality of life, health, and well-being

- Extent to which the interior design complements the exterior architecture 
- Environmental sustainability of materials

- Appropriateness, effectiveness, and attractiveness of the building's floor plan to the intended occupant(s)

- Overall approach to lighting, including specified equipment and control scenarios, and analysis of electric lighting and daylighting for specific rooms

- Overall approach to and specification of plug loads and appliances that are energy efficient, appropriate for the needs of the occupants, and responsive to modern techniques and capabilities, including operational schedules to meet the needs of building occupants.

\subsubsection{Resources}

DOE Zero Energy Ready Home

ENERGY STAR Energy Efficient New Homes

LEED Guide to Certification: Homes

Kruger, A., and C. Seville. 2012. Green Building: Principles and Practices in Residential Construction (Go Green with Renewable Energy Resources). Independence, KY: Cengage Learning.

Foster, K., A. Stelmack, and D. Hindman. 2014. Sustainable Residential Interiors, $2^{\text {nd }}$ edition. Hoboken, NJ: John Wiley and Sons.

Residential Energy Services Network, Lighting, Appliance and Miscellaneous Energy Usage Profile Amendments

Lighting Research Center Energy Efficient Residential Lighting

ASHRAE GreenGuide

ENERGY STAR Efficient Lighting and Appliances

Commercial Buildings Resource Database

50\% Advanced Energy Design Guide for K-12 Schools

Technical Support Document: Development of the Advanced Energy Design Guide for K-12

School Buildings for $50 \%$ Energy Savings

Advanced Energy Design Guide for Zero Energy K-12 Schools

Achieving 50\% Energy Savings in New Schools

$\underline{\text { Technical Feasibility Study for Zero Energy K-12 Schools }}$ 


\section{Lighting Design Lab}

\section{Lighting Design Lab Footcandle Light Guide}

\subsection{Energy Analysis}

The basis of high-performance buildings is grounded in energy analysis. Early energy analysis demonstrates how the various efficiency features interact to reduce whole-building energy use.

\section{Residential}

The residential building industry often uses the Home Energy Rating System (HERS) Index to indicate energy efficiency. A lower score signifies a more energy-efficient home. To determine the score, homes are compared to a benchmark based on the 2006 International Energy Conservation Code. The HERS score can be calculated by using any accredited HERS software.

HERS rating software calculates heating, cooling, hot water, lighting, and appliance energy loads, consumption, and costs for new and existing single-family and multifamily homes. One of the industry-accredited programs, REM/Rate ${ }^{\mathrm{TM}}$, is provided to teams at no charge after completing the team application; however, using it is not required.

Energy-efficiency optimization can be calculated through a variety of software programs. One option, BEopt ${ }^{\mathrm{TM}}$ (Building Energy Optimization), provides capabilities to evaluate residential building designs and identify cost-optimal efficiency packages at various levels of whole-house energy savings along the path to zero energy. The BEopt software is free to download; however, using it is not required.

\section{Commercial}

Commercial buildings are often evaluated on their EUI, which is measured as the total energy consumed annually divided by the gross floor area (kilo-British thermal unit/square foot or kiloBritish thermal unit/square meter). These numbers can be calculated with respect to source energy as well as site energy. Source energy accounts for all the upstream losses associated with converting and transporting energy to the building site. It is calculated by taking the site energy and applying a site to source multiplier for each energy source. See the resources for more information and examples. Alternative metrics for comparison are also useful, such as energy divided by total students (kilo-British thermal unit/student).

OpenStudio ${ }^{\circledR}$ is an energy simulation software used to model complexities of integrating daylighting, lighting, and heating and cooling equipment often found in commercial buildings. It has an intuitive graphical user interface that helps users navigate through different inputs for the energy model. A unique feature of OpenStudio is that it provides the capability to quickly implement different energy-efficiency and energy conservation strategies using a set of instructions called measures. OpenStudio can be used to evaluate the impact of energyefficiency and energy conservation strategies on the EUI of the building and ensure that it is 
along the path to zero energy. OpenStudio is free to download; however, using it is not required.

\subsubsection{Criteria}

The jury evaluates each submission according to the following criteria:

- Comprehensive energy efficiency analysis showing the optimal interaction of efficiency features among design elements

- Appropriateness of the technology options chosen for the location and climate

- Quality of the building annual energy consumption calculations

- Opportunities, trade-offs, and design modifications needed to incorporate renewable energy systems sufficient to achieve zero annual energy use and offset nonrenewable energy sources

- Design and component analyses for active renewable energy systems necessary to achieve zero energy use among all building loads.

- Residential: The final plan-based residential HERS Index score calculated with and without renewable energy systems

- Commercial: The EUI of the school (without renewable systems) and ability to offset it with on-site renewable energy.

\subsubsection{Resources}

DOE Zero Energy Ready Home National Program Requirements (Rev. 06)

DOE Guidelines for Participating in the DOE Zero Energy Ready Home

DOE A Common Definition for Zero Energy Buildings

ENERGY STAR Renewable Energy Ready Homes

Florida Solar Energy Center Zero Energy Homes

$\underline{\text { NREL PVWatts }}$

NREL BEopt

$\underline{\text { NREL OpenStudio }}$

NORESCO REM/Rate

EnergyGauge Energy and Economic Analysis Software

DOE Zero Energy Building Definition 


\section{U.S. Environmental Protection Agency (EPA) Technical Reference: Source Energy}

\section{ASHRAE Standard 105-2014}

Toolkit: K-12 Solutions for Building Energy Excellence

\subsection{Constructability}

Construction details are important for clear and precise communication to trade professionals and others who are responsible for reviewing or building the design, as well as for the technical analysis of the design. Well-drafted details in the drawings clarify design elements and help ensure that a team's design is successfully implemented.

\subsubsection{Criteria}

The jury evaluates each submission according to the following criteria:

- How effectively the drawings and associated documentation communicate the design and would enable successful review and construction by industry professionals, including tradespeople, suppliers, fabricators, code reviewers, and purchasers

- Proactive design and detailed approach to prevent common problems in construction, which often occur at transitions or discontinuities in control layers (e.g., water, air, thermal, vapor)

- Level at which typical construction practices by readily available labor are considered part of the design process and final project solution.

\subsubsection{Resources}

American Institute of Architects Construction Documentation Drawings

Building America Strategy Guideline: Advanced Construction Documentation Recommendations for High Performance Homes

EPA Moisture Control Guidance for Building Design, Construction, and Maintenance

Oak Ridge National Laboratory Building Foundations Handbook, Basement

Construction Details

Connecticut Zero Energy Challenge

AlA Committee on the Environment

Building Science Corporation Measure Guideline-Deep Energy Enclosure Retrofit for Interior Insulation of Masonry Walls 


\subsection{Financial Analysis}

The purpose of the financial analysis is to relate the team's unique design to the marketplace by estimating the overall cost of ownership. Elements of the financial analysis include the estimated costs of construction, financing, insurance, taxes, monthly utilities, and maintenance.

Teams are expected to complete the financial analysis form provided by the organizers and explain all values entered. The form is posted to the Race to Zero Groups.io portal.

\subsubsection{Criteria}

The jury evaluates each submission according to the following criteria:

- Quality of the construction cost analysis completed based on standard cost databases such as RSMeans or standard cost data provided by DOE, including federal, state, and local financial incentives for using renewables or energy-efficiency upgrades

- Integration of the utility cost estimate based on the energy analysis, including proper selection of a local rate tariff appropriate for the building size and type

- Quality of the maintenance cost analysis

- Residential: Affordability of the design for the targeted homeowner(s), including the necessary income required to comfortably afford the financial outlay

- Commercial: Cost-effectiveness of the design for the targeted school district, including the costs for the initial construction as well as the expected operation and maintenance compared to other schools in the region.

\subsubsection{Resources}

Description of the NREL National Residential Efficiency Measures Database

National Residential Efficiency Measures Database

$\underline{\text { RSMeans }}$

$\underline{\text { NREL BEopt }}$

Database of State Incentives for Renewables \& Efficiency ${ }^{\circledR}$

OpenEI Database

\subsection{Envelope Performance and Durability}

The building envelope separates the conditioned environment from the outdoor environment and encloses all the systems in the building. The building envelope includes the foundation, walls, windows, doors, and roof.

\subsubsection{Criteria}

The jury evaluates each submission according to the following criteria: 
- Design's consideration of major mechanisms that affect envelope durability and integrate the building science concepts of air transportation, moisture management, and thermal and hygrothermal performance based on specific environmental conditions

- Level at which construction details and material specifications address the physical principles to control air movement based on air sealing and air barrier designs

- Level at which specifications address thermal control using insulation systems that are properly installed, without gaps, voids, compression, and/or thermal bridging

- Level at which specifications address comprehensive water and moisture management, including flashing details, water barriers, and capillary breaks to control bulk moisture; control of moisture movement through the wall system; and considerations for other potential moisture problems (e.g., condensation)

- Design's consideration of resiliency related to prevalent natural disaster risks for the project's location.

\subsubsection{Resources}

ASHRAE (several relevant resources available)

ASHRAE Handbook-Fundamentals (Edition 2017)

$\underline{\text { DOE Building Technologies Office Building, Science Education }}$

DOE Zero Energy Ready Home Recommended Quality Management Provisions

$\underline{\text { Pacific Northwest National Laboratory, Building Science Publications }}$

EPA Moisture Control Guidance for Building Design, Construction and Maintenance

Efficient Windows Collaborative

Oak Ridge National Laboratory Foundation Design Handbook

National Institute of Building Sciences Whole Building Design Guide

WUFI

EPA, Moisture Control Guidance for Building Design, Construction and Maintenance (Note Appendix A, Pen Test)

$\underline{\text { John Straube, High Performance Enclosures }}$

\subsection{Indoor Air Quality and Ventilation}

Indoor air quality (IAQ) can significantly impact the health and comfort of occupants. Many factors can affect IAQ, including ventilation rates and methods, contamination sources and control, and effective filtration. 


\subsubsection{Criteria}

The jury evaluates each submission according to the following criteria:

- Overall approach and details of the IAQ contaminant control and filtration solutions used to provide a healthy indoor environment

- Overall approach and details of ventilation systems for occupant health and comfort

- Appropriate consideration of materials, details, and specifications to improve IAQ

- Approach of the design to limit the introduction of contaminants in the material selections and the operation of the building.

\subsubsection{Resources}

\section{EPA Indoor airPLUS Program}

National Institute of Building Sciences, Whole Building Design Guide

ASHRAE 10 Tips for Home Indoor Air Quality

Lawrence Berkeley National Laboratory, Indoor Air Quality Scientific Findings

Resource Bank

WELL Building Standard

Green Globes

Armin Rudd, Ventilation Guide

ASHRAE Standard 55

ASHRAE Standard 189.1

$\underline{\text { Indoor Air Quality Association }}$

\subsection{Mechanical, Electrical, and Plumbing Design}

The space-conditioning system is designed to maintain comfort conditions via successful temperature control, humidity control, air mixing, and distribution systems. Optimal comfort conditions depend on and respond to the interactions of climate and building envelope.

Space-conditioning system selection and design involve choosing the appropriate technology and evaluating the system performance, installed cost, reliability, operation and maintenance costs, and environmental performance.

Responsible water use is a result of appropriately selected fixtures, occupant behavior, and energy-efficient domestic water systems. 


\subsubsection{Criteria}

The jury evaluates each submission according to the following criteria:

- Approach to choosing and meeting performance objectives for the mechanical system equipment size, selection, and integration to maximize energy efficiency without compromising occupant comfort

- Systems approach to integrating architecture and engineering relative to the building envelope and climate through operation and control, thermal conditioning for each type of space, and energy source options

- Consideration of the maintenance requirements and ability to measure and verify performance

- Potential for control of plug loads; large appliances; lighting; heating, ventilating, and air conditioning (HVAC); and general miscellaneous electric loads

- Application of technologies to automate the control of energy use and provide energy information that can reduce energy consumption and costs

- Overall design principles of the water system, including the selection of water conservation fixtures, estimated loads, water heating equipment, supply piping, rainwater or gray water systems, and the hot water plumbing layout to minimize wait time, losses, and wasted water.

\subsubsection{Resources}

DOE Building America Solution Center

$\underline{\text { Pacific Northwest National Laboratory Building Science Publications }}$

ACCA Resources

ACCA Spreadsheets, Technical Manuals, Standards

ENERGY STAR Heat and Cool Efficiently, Maintenance Checklist

ASHRAE Education \& Certification Fundamentals of Air System Design

Advanced Strategy Guideline: Air Distribution Basics and Duct Design

$\underline{\text { Trane }^{\circledR} \text { VariTrane }^{\mathrm{TM}} \text { Duct Designer }}$

Elite Software Ductsize-HVAC Duct Sizing and Analysis

$\underline{\text { Wrightsoft }}{ }^{\oplus}$, HVAC Design and Sales Software

Design Master, Duct Layout 
Lawrence Berkeley National Laboratory Hot Water Draw Patterns in Single-Family Houses

NREL Tool for Generating Realistic Residential Hot Water Event Schedules

Building America Top Innovations Profile: Model Simulating Real Domestic Hot Water Use

EPA WaterSense

$\underline{\text { ASHRAE Standard } 55}$

ASHRAE Standard $62.1 \& 62.2$

ASHRAE Standard 90.1

$\underline{\text { ASHRAE Standard } 189.1}$

Technical Feasibility Study for Zero Energy K-12 Schools

\subsection{Innovation}

The building industry can often be slow to adopt the latest building science technologies and best practices. Unique and innovative approaches to smart building design and construction that improve the status quo are necessary to transform the nation's energy future. This evaluation parameter seeks to award points to teams that take an innovative and beneficial approach to addressing building architecture and reaching the goals of the zero energy ready buildings while addressing suitability for mainstream builders. The jury evaluates innovation among all design criteria and within each scoring parameter.

\subsubsection{Criteria}

The jury evaluates each submission according to the following criteria:

- Overall approach to the design competition regarding the integration of innovations that improve the design solution and support elementary school education opportunities

- Unique integration of building science principles in ways that are achievable, beneficial, cost-effective, and functional

- Integrative, interdisciplinary solutions that enhance synergies among building subsystems

- Smart consideration and development of unique design parameters in the submission that respond to a market need, such as regional and local issues

- Collaboration with industry partners to evaluate and provide feedback on innovations.

\subsubsection{Resources}

Building America: Bringing Building Innovations to Market

Building America Top Innovations 
$\underline{\text { DOE Housing Innovation Awards }}$

National Institute of Building Sciences Innovation Conference Proceedings

U.S. Department of Housing and Urban Development: The Diffusion of Innovation in the Residential Building Industry

$\underline{\text { DOE Teach and Learn }}$

National Energy Educational Development Project

\subsection{Presentation and Documentation Quality}

Presentation quality often determines how a client receives and implements work and how effectively innovation is adopted. Complete and consistent documentation clearly conveys the goals of the team and its design. Presentations should tell the story of the project without verbose language or cluttered slides. Planning ahead for spoken presentations, coordinating deliverables, and focusing on the visual representation of complex data can increase audience interest and commitment to the ideas presented.

\subsubsection{Criteria}

The jury evaluates each presentation according to the following criteria:

- Completion and quality of project submissions

- Quality of presentation package of visual aids and spoken remarks

- Timeliness of project submissions.

\subsubsection{Resources}

2017 Race to Zero Presentations

2016 Race to Zero Presentations

Ignite ${ }^{\circledR}$ Presentations

$\underline{\text { TED Talks }}$

AlA Committee on the Environment

$\underline{\text { PG\&E Zero Net Energy Program }}$

DOE-Hosted Presentations 


\subsection{Evaluation Rating Scale}

The jury evaluates each parameter according to the following scale:

Table 2. Evaluation Scale

\begin{tabular}{ll}
\hline $\mathbf{0 - 1}$ & Missing all items; no explanation of how the design addresses the criteria \\
\hline $\mathbf{2 - 3}$ & Missing some items; minimal explanation of how the design addresses the criteria \\
\hline $\mathbf{4 - 5}$ & All minimum requirements met; minimal explanation of how the design addresses the criteria \\
\hline 6-8 & All minimum requirements met; full explanation of how the design addresses the criteria \\
\hline $\mathbf{9 - 1 0}$ & $\begin{array}{l}\text { All minimum requirements met; distinguished excellence in the explanations describing how } \\
\text { the design exceeds the criteria }\end{array}$ \\
\hline
\end{tabular}

\subsection{Contest Evaluation Process}

The evaluation process is multilayered and includes the following:

- Contest juror panels (each with three to five jurors) assess the team designs.

- One jury convenes for each of the five design contests. Each juror panel assesses up to eight team designs.

- Individual contest jurors assign preliminary scores based on the Project Reports.

- Preliminary contest scores are modified by the jurors based on the Project Presentations and question-and-answer period during the final evaluation.

- Contest jurors assign an integer value from 0-10 for each parameter and sum them to determine each team's total score.

- Contest juror panels select first- and second-place award winners in each contest based on the following attributes. Note: If both the first- and second-place award winners in a contest are graduate student teams, then the jurors also select a top undergraduate team award winner.

- Highest average scores for the juror panel

O Excellence in meeting the overall design intent of the competition

- Demonstrates an excellent level of understanding in the parameter subject areas.

- The five first-place award winners each deliver a 10-minute presentation at the Awards Banquet.

\subsection{Grand Jury Evaluation Process}

A grand jury selects a Grand Winner from among the five first-place teams based solely on the short 10-minute presentations given at the Awards Banquet. 
The grand jury enters the review process with the understanding that the five first-place winners have demonstrated a design that represents the quality expected for high-performance buildings through the details listed in Section 3.12, Contest Evaluation Process.

The grand jury is tasked with evaluating whether the design meets the needs of the building occupants and owners. The 10-minute summary presentations are evaluated against the following criteria:

- Quality of the architectural design and aesthetics

- Design functionality for the occupants

- Comprehensive energy-efficiency features among design elements

- Appropriateness of the design for the location and climate

- Proactive design to enable successful construction

- Cost-effectiveness of the design for the target market

- Innovative integration of solutions that are achievable, beneficial, and cost-effective

- Quality of presentation package of visual aids and spoken remarks.

The grand jury evaluates each of these criteria on the scale shown in Section 3.11, Evaluation Rating Scale, to facilitate their selection of the Grand Winner. 


\section{Appendix A: Project Introduction Submission Instructions}

The Project Introduction provides the information necessary to communicate the salient points of the projects to all competition participants. It should be considered a high-level summary to describe the project and provide key points.

Teams submit the Project Introduction first as a standalone document and then integrate into the Progress Report and the Project Report.

A template is available on the Race to Zero website and the Race to Zero Groups.io portal for the Project Summary portion of the Project Introduction; past project summaries can be viewed on the Race to Zero website. The template uses filler text as a placeholder for the content that your team inserts. It is understood that for the initial submission, the project details might be considerations, aspirations, or otherwise tentative and subject to change in future submissions.

\section{Format Requirements}

- Paper size: Standard 8.5 inches $\times 11$ inches (216 millimeters $\times 279$ millimeters), ANSI A

- Formatting: Single-spaced, 11-point font for body text (diagrams may have smaller fonts)

- Borders: 0.5-inch (12.7-millimeters) minimum, except for tables, figures, and images

- Maximum page length: Three, for the optional Project Introduction submission

- File type: Single, bookmarked PDF

- File size: Less than $10 \mathrm{MB}$

- File name: See instructions in Appendix F.

\section{Content Requirements}

1. Project Summary (1-page maximum for all submissions)

- List your project name, team name, contest, and collegiate institution(s) in the header.

- Replace the logo in the upper right corner with your team or collegiate institution's logo.

- Replace the building image with one or two graphics that best represent your project.

- Provide a concise description of the project, including a brief identification of the target market.

- Describe the relevance of your project to the goals of the competition.

- Summarize your design strategy and relevant key points.

- List the relevant project data. 
- Provide technical specifications for your project.

2. Team Information

- Include an academic institution profile with particular focus on building science coursework, extracurricular activities, or resources.

- Include the names of the student team members, their academic majors, and levels; identify the student team lead.

- Include a summary of industry partners and form of support.

3. Project Highlights

- Note the structural and mechanical systems.

- Include a floor plan, exterior renderings, and interior renderings.

\section{Feedback Criteria}

The organizers provide feedback on the following:

- Compliance with contest definition

- Submission formatting compliance. 


\section{Appendix B: Project Progress Report Submission Instructions}

The Project Progress Report provides an interim submission to demonstrate the team's progress toward completing the Project Report. It includes an updated Project Introduction with additional project information and details.

Teams also submit this Project Progress Report, including a further refined Project Introduction, with the Project Report.

Note: English units of measurement are preferred; however, a submission with metric units would be accepted. If metric units are used, state metric units first, followed by English equivalents in parentheses. Example: 38.1 meters (125 feet). For quick online conversions of English units of measurement to metric units, see the Digital Dutch Unit Converter or the Internet French Property Measuring Units Converter Table.

\section{Format Requirements}

- Paper size: Standard 8.5 inches $\times 11$ inches (216 millimeters $\times 279$ millimeters), ANSI A

- Formatting: Single-spaced, 11-point font for body text (diagrams may have smaller fonts); add page numbers for convenience of the reviewers

- Borders: 0.5-inch (12.7-millimeters) minimum, except for tables, figures, and images

- Maximum page length: No more than 10 pages; the cover, back pages, and table of contents are not included in this count

- File type: Single, bookmarked PDF

- File name: See instructions in Appendix F.

\section{Content Requirements}

- Table of Contents

- List of Tables

- List of Figures

- Project Introduction (up to 6 pages; see Appendix A)

- Design Constraints Description (1-3 pages), including:

- Summary of the lot location, size, shape, orientation, climate, and relationship to $\operatorname{road}(s)$

- Summary of the intended occupants and their characteristics

- Identification of any programs or standards that form the basis for design and their roles in achieving the goals of the competition 
- Description of the neighborhood and/or community setting, including density, access to, and reliance on various transportation modes

- Design Goals (1 page)

- Summarize the goals the team considered when creating and developing the design.

\section{Evaluation Criteria}

The organizers evaluate the submissions according to the following criteria:

- Compliance with contest definitions

- Compliance with submission formatting

- Quality of design strategy constraints and goals

- Level of inclusion and completion of content

- Other factors, such as geographic and technology diversity, are considered for the benefit of the program. 


\section{Appendix C: Project Report Submission Instructions}

The Project Report provides a complete submission to be reviewed by jurors in advance of the competition. It includes an updated Project Introduction as well as construction details and evaluation parameter narratives.

A team's Project Report should be organized into three parts: Volume I: Project Report, Volume II: Supporting Documentation, and Project Images. Only Volume I and Project Images are required. Images are used by organizers to recognize individual team performance or for outreach, as appropriate.

Volume I is limited to 40 pages and must include all the information the team deems essential to portraying its competition solution to the jury. A summary and discussion of analytical results should be provided in Volume I; supporting information-such as detailed calculations or equipment data sheets-should be relegated to Volume II. Citations may be in the team's chosen format, but they should be consistent throughout the submission.

\section{Format Requirements}

- Volume I: No more than 40 pages; the cover, back page, and table of contents are not included in this count. Pages must be numbered. Front matter page numbers can use Roman numerals (e.g., i, ii...iv).

- Volume II: 100-page limit. Pages must be numbered. The jurors evaluating your submission have a limited amount of time to review the entire submission, so teams should plan accordingly. Jurors might not read all of Volume II in detail, and jurors are not expected to open any hyperlinks contained within.

- Paper size: Standard 8.5 inches $\times 11$ inches (216 millimeters $\times 279$ millimeters), ANSI A

- Formatting: Single-spaced, 11-point font for body text (diagrams may have smaller fonts)

- Borders: 0.5-inch (12.7-millimeters) minimum, except for tables, figures, and images

- File type: Single, bookmarked PDF

- File name: See instructions in Appendix F.

Note: English units of measurement are preferred; however, a submission with metric units would be accepted. If metric units are used, state metric units first, followed by English equivalents in parentheses. Example: 38.1 meters (125 feet). For quick online conversions of English units of measurement to metric units, see the Digital Dutch Unit Converter or the Internet French Property Measuring Units Converter Table.

\section{Content Requirements}

Volume I: Project Report

- Table of Contents

- List of Tables 
- List of Figures

- Section 1: All content of the Progress Report, including the introduction and updates as desired (up to 10 pages; see Appendix B)

- Section 2: Evaluation parameter narratives, including relevant images and figures (1-30 pages)

1. Architectural Design

2. Interior Design, Lighting, and Appliances

3. Energy Analysis

4. Constructability

5. Financial Analysis

6. Envelope Performance and Durability

7. Indoor Air Quality (IAQ) and Ventilation

8. Mechanical, Electrical, and Plumbing Design

9. Innovation.

- Appendices (required)

A. Design renderings (3 to 10 )

B. Construction drawings (up to 15 pages, no bigger than 11 inches $\times 17$ inches, or 279 millimeters $\times 432$ millimeters)

1. Site plan

2. Dimensioned floor plan(s)

3. Building elevations (all)

4. Building sections

5. Interior details, including a rendered floor plan showing typical furniture layout and option details on finishes, cabinetry, and other fixtures

6. Wall, floor, and roof sections

7. Typical window and door details (including flashing), schedule, and specifications

8. Air sealing details

9. Mechanical plans and schedules*, indicating duct sizing and layout, equipment locations and specifications, control design and specifications, and minimum installation requirements

10. Plumbing plans and schedules*, including fixture locations, piping system layout and design, equipment location and specifications, and minimum installation requirements 
11. Electrical and lighting plans and schedules*, including outlet locations, fixture specifications, installed lighting (watt/square foot, or watt/square meter) levels, cooling system capacity diagrams (tons/ $\mathrm{ft}^{2}$, or kilograms/square meter), control systems, and photovoltaic systems

* For the commercial contest, teams should indicate system type, size, and quantity; however, full system layout and specifications are not required.

C. Energy analysis

Residential: HERS Index rating documentation summary

1. Include the house size adjustment factor calculations as required for homes exceeding the area specified in the size adjustment factor table.

2. Perform a HERS Index analysis to include the home with and without the renewable energy system.

Commercial: EUI target documentation summary

1. Summarize major inputs for energy model including envelope characteristics, lighting power densities, plug load densities, HVAC sizing capacities, HVAC system efficiencies, and overview equipment schedules.

2. Demonstrate compliance with Table 2, "EUI Targets to Meet or Exceed Zero Energy" of the Technical Feasibility Study for Zero Energy K-12 Schools for the proposed school's climate zone. EUI's should be provided in both site and source metrics. Show summary calculations of the potential for on-site renewable energy to offset the energy consumption of the building on a source basis.

D. Financial analysis summary using provided template and appropriate references.

\section{Volume II: Supporting Documentation}

This is optional and might not be read in detail by jurors. This includes additional documentation to support the team's design goals and submission, such as energy analysis reports, equipment specifications, quantity takeoffs, supplemental construction details, or supporting design calculations.

\section{Project Images}

- Include two images that best represent the project, such as renderings, drawings, photographs of scale models, or other team-generated content.

- Include one image of your team.

- Ensure that the images have a minimum resolution of $1,920 \times 1,080$.

- Ensure the images have an aspect ratio of 16:9.

- Submit the images as files such as .jpg, .tiff, or .png. 


\section{Appendix D: Project Presentations Submission Instructions}

Each team develops two presentation files for the competition event.

1. Contest presentation: A 25-minute presentation on the project to be delivered in person to the jurors during the event, with an additional 10 minutes for questions, for a total 35-minute team presentation.

2. Grand jury presentation: A 10-minute presentation with no additional time reserved for questions. First-place winners in each contest category give a 10-minute presentation to the grand jury as well as all competition participants during the Awards Banquet. (See Section 3.13, Grand Jury Evaluation Process.)

To ensure all electronically submitted materials work with the organizer's presentation computers, teams are encouraged to embed all videos in the team submission and to notify the organizers before arriving at the competition to allow organizers to ensure that the appropriate software is available to play the video.

Name the files according to the instructions in Appendix F. 


\section{Appendix E: Project Poster Submission Instructions}

Each team may develop a project poster that showcases its design and response to contest parameters. A Poster Session during the event displays all team projects.

- Content should, at a minimum, include the project summary as described in Appendix A.

- A team may include additional information, graphics, and images, as desired.

- The poster should be 3 feet wide $\times 2$ feet tall ( 0.9 meters wide $\times 0.6$ meters tall).

- Submit the poster as a PDF.

- Name the file according to the instructions in Appendix F.

- Teams should print their poster and bring it to the competition event. 


\section{Appendix F: Electronic File-Naming Instructions}

Project submissions are considered on time if they are uploaded to the Race to Zero file submission link by 5:00 p.m. Eastern Time on the due date. See the Summary of Important Dates section and the corresponding appendices for required file formats for each of the respective project submissions. Teams are encouraged to submit their projects at least a few hours before to the deadline to ensure they are received. Jurors receive notifications about late project submissions.

All electronic files should be uploaded via the file submission link posted to the Race to Zero Groups.io portal; instructions for using the file submission link are available on the Groups.io portal.

The required file-naming convention for all electronic files is as follows:

[COLLEGIATE SHORT NAME]_[CONTEST ABBREVIATION]_[DELIVERABLE ABBREVIATION]_[SUBMISSION DATE (YYYY-MM-DD)].[EXTENSION]

Following is a list of contest and deliverable abbreviations. Collegiate short name abbreviations are made available on the Race to Zero Groups.io portal in a separate document.

Example: A Project Progress Report submitted on February 20, 2018, by Illinois State University team in the urban single-family contest would have the following file name:

IllinoisState_USF_PROGRESS_2018-02-20.pdf.

\section{Contest abbreviations:}

- Suburban Single-Family: SSF

- Urban Single-Family: USF

- Attached Housing: $\mathrm{AH}$

- Small Multifamily: SMF

- Elementary School: ES

\section{Deliverable abbreviations:}

- Project Summary: SUMMARY

- Project Introduction Report: INTRO

- Project Progress Report: PROGRESS

- Project Report Volume I: VOLI

- Project Report Volume II: VOLII 
- Project Presentation-25-minute: PRESCONTEST

- Project Presentation-10-minute: PRESGRAND

- Project Poster: POSTER

- Project Photo 1: PHOTO1

- Project Photo 2: PHOTO2

- Team Photo: TEAMPHOTO 
"Working with a team gave me a chance to better understand how to converge on a design and what is contributed by architects, building scientists, engineers, and estimators. Working toward a competition where we knew we would gain visibility for the project helped motivate us to design something of a quality that we would be proud of."

- 2017 Race to Zero Student

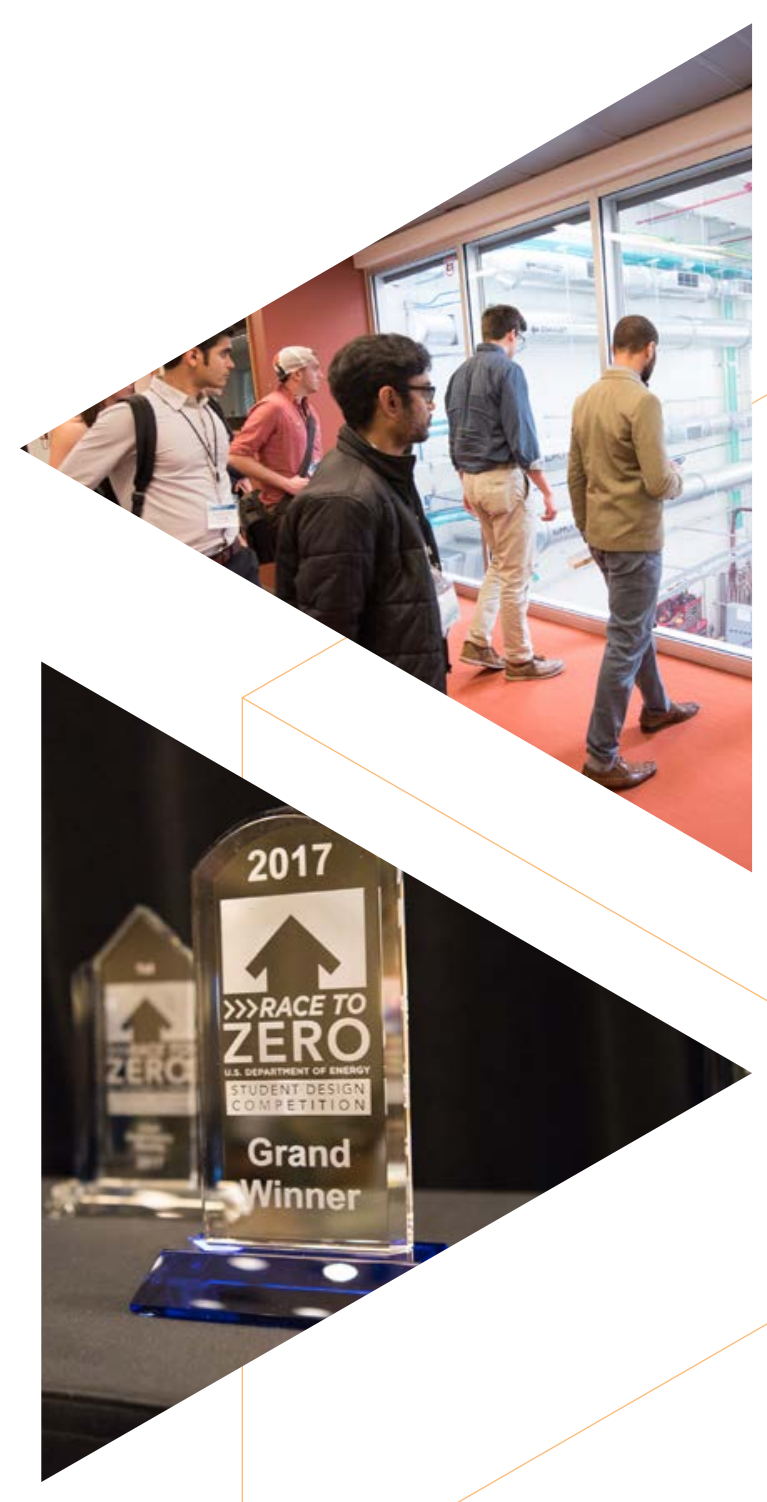

"The competition encouraged collaboration with local industry partners, which increased the rate at which students were able to process through the various design phases and topics. The industry collaboration and real-world design scenario also added a practical motivation that stretches students beyond classroom examples."

- 2017 Race to Zero Faculty Advisor

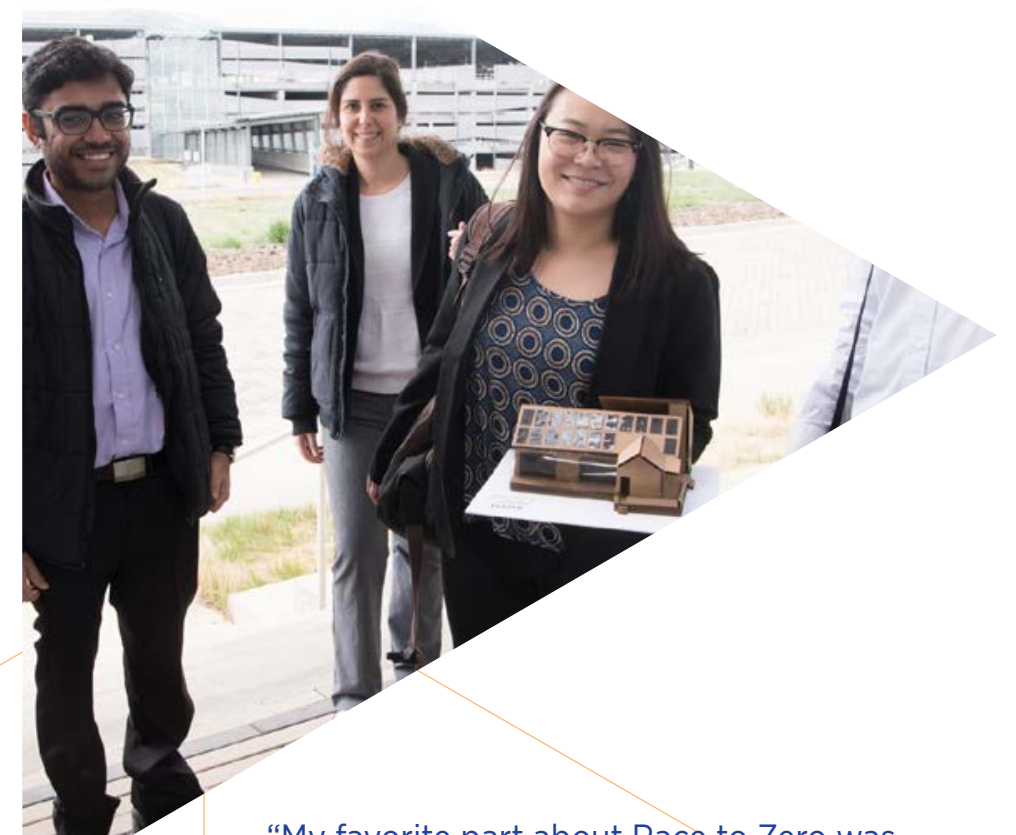

"My favorite part about Race to Zero was hearing from each submission and learning about all the ideas each team came up with. As a student and future construction professional I walked away with many ideas about how to create zero or low energy homes on a real world level."

- 2017 Race to Zero Student

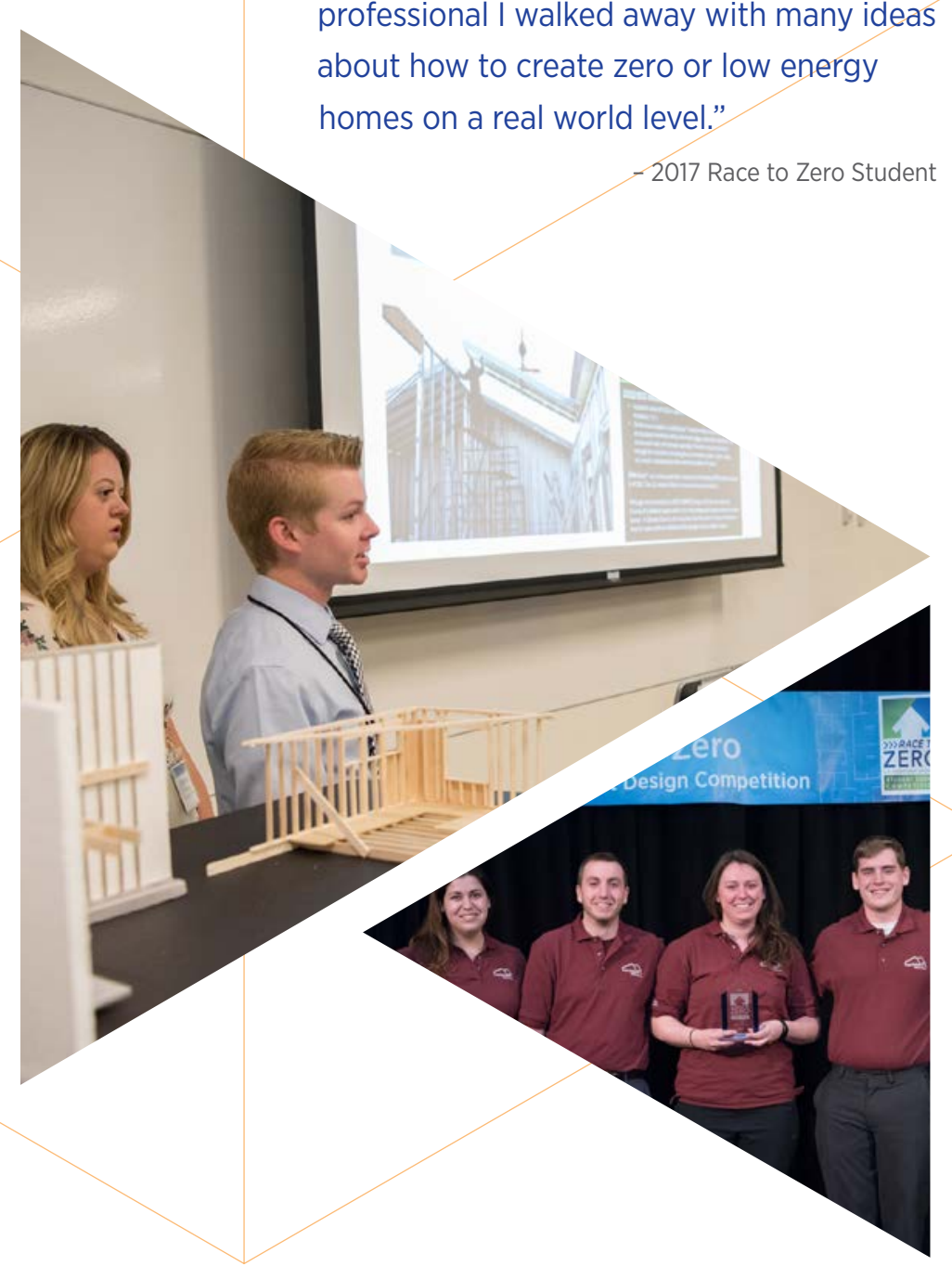


Sponsors
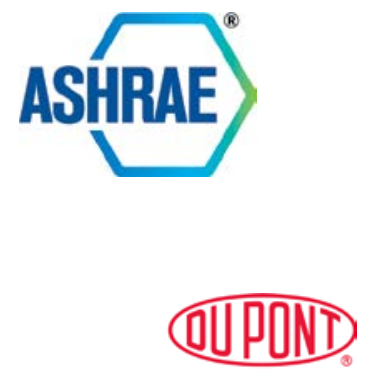

Tyvek.
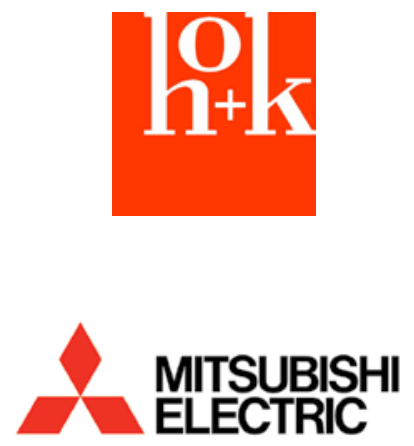

COOLING \& HEATING

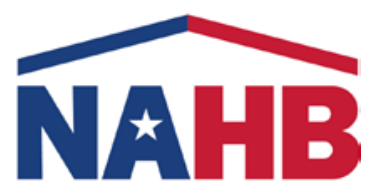

$\mathrm{NQRESCO}$

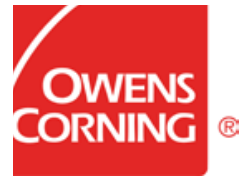

(2) Plastics

PIPE

INSTITUTE ${ }^{\oplus}$

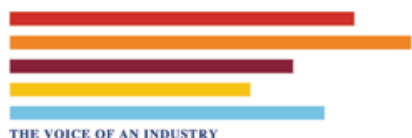

THE VOICE OF AN INDUSTRY

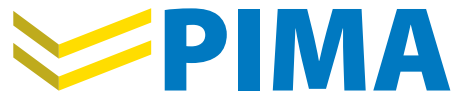

POLYISOCYANURATE INSULATION MANUFACTURERS ASSOCIATION
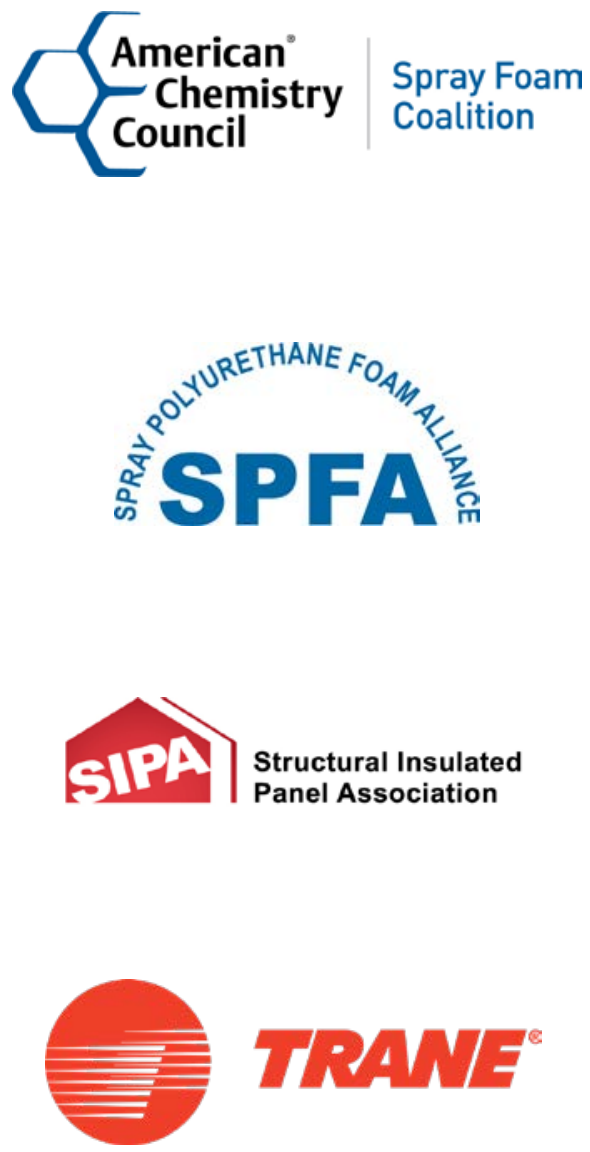


\section{ACKNOWLEDGMENTS}

U.S. Department of Energy Building Technologies Office

National Renewable Energy Laboratory

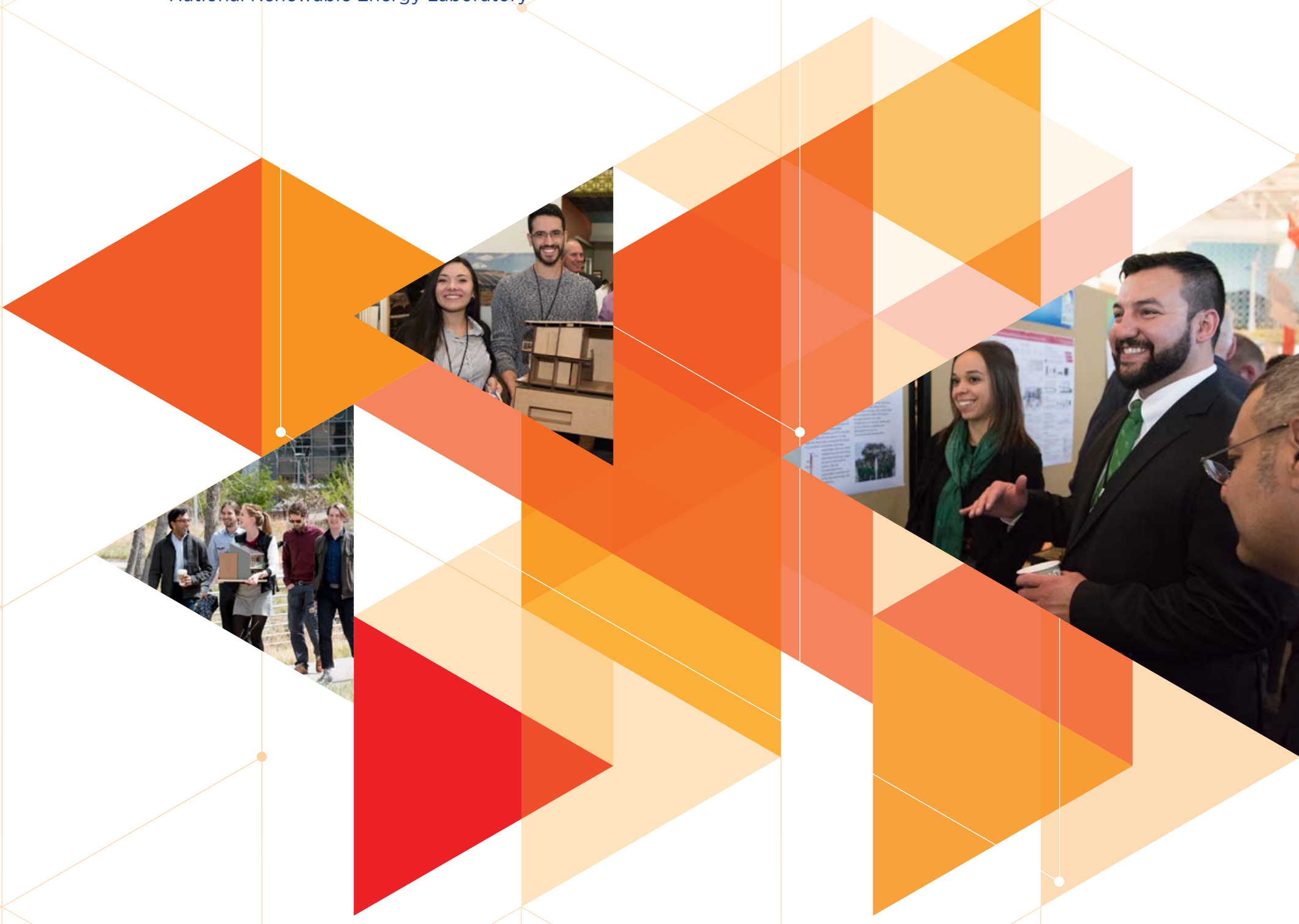

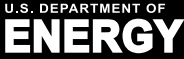

For more information, visit: energy.gov/eere

DOE/GO-102018-4974 January 2018
Prepared by the National Renewable Energy Laboratory (NREL) NREL is a national laboratory of the U.S. Department of Energy Office of Energy Efficiency and Renewable Energy Operated by the Alliance for Sustainable Energy, LLC All photos from Ellen Jaskol 